\title{
Régimen tributario aplicable a las universidades en el Perú
}

Gonzalo Echevarría Mey

Abogado por la Universidad de Lima.

SUMARIO:

I. Antecedente normativo y disposiciones legales vigentes.

II. Inafectación de impuestos o exoneración de tributos.

III. Régimen tributario vigente de las universidades.

1. Impuesto a la Renta;

2. Impuesto General a las Ventas;

3. Impuesto Predial;

4. Alcabala;

5. Arbitrios.

IV. Conclusiones. 


\section{ANTECEDENTE NORMATIVO $Y$ DISPOSICIONES LEGALES VIGENTES}

El artículo 19 de la Constitución Política del Perú de 1993 establece que "(...) las universidades, institutos superiores y demás centros educativos constituidos conforme a la legislación en la materia gozan de inafectación de todo impuesto directo e indirecto que afecte los bienes, actividades y servicios propios de su finalidad educativa y cultural (...) en materia de aranceles de importación, pueden establecerse un régimen especial de afectación para determinados bienes (...)".

Por su parte, el artículo 87 de la Ley 23733 - Ley Universitaria señala que: "(...) las universidades están exoneradas de todo tributo fiscal o municipal creado o por crearse (...) y las actividades culturales que ellas organizan se encuentran exentas de todo impuesto (...) la exoneración de los tributos a la importación se limita a los bienes necesarios para el cumplimiento de sus fines (...)".

Finalmente, el artículo 11 del Decreto Legislativo 882 - Ley de Promoción de la Inversión en la Educación, establece que las instituciones educativas particulares ${ }^{1}$ se rigen por las normas del Régimen General del Impuesto a la Renta. Para estos efectos, debe tenerse presente que el inciso i) del artículo 28 de la Ley del Impuesto a la Renta señala que son rentas de tercera categoría las obtenidas por las instituciones educativas particulares, habiéndose previsto una exoneración del Impuesto a la Renta hasta el 31 de diciembre de 2011 aplicable a las instituciones educativas que funcionen como asociaciones civiles, de conformidad con lo dispuesto por el inciso b) del artículo 19 de la citada Ley.

De la lectura de las normas mencionadas surgen dos interrogantes: a. ¿Cuál es el beneficio real aplicable a las universidades? ¿se trata de una inafectación, de una exoneración o de ambos?

b. Dicho beneficio, cualquiera sea su naturaleza, ¿alcanza a todos los tributos o sólo a los impuestos?

A continuación analizaremos ambas interrogantes.

\section{INAFECTACIÓN DE IMPUESTOS O EXONE- RACIÓN DE TRIBUTOS}

Para poder determinar si el beneficio de las universidades califica como una inafectación o una exoneración, previamente debemos hacer referencia a la Constitución Política de 1979, la cual establecía que: "(...) las universidades y los centros educativos y culturales están exonerados de todo tributo, creado o por crearse (...) la ley establece estímulos tributarios y de otra índole para favorecer las donaciones y aportes a favor de las universidades y centros culturales".

Es bajo la vigencia de dicha norma constitucional, que el 17 de diciembre de 1983 se publica la Ley 23733 - Ley Universitaria, a través de la cual se dispuso que las universidades se encuentren exoneradas de todo tributo.

Con la entrada en vigencia de la Constitución de 1993, se produce un cambio en el régimen tributario de las universidades, toda vez que su artículo 19 modificó el alcance del beneficio creado, pasando de una exoneración (según se preveía en la Constitución de 1979) a una inafectación.

Es importante señalar que la inafectación constituye un beneficio más amplio que el de la exoneración. Bajo esta última lo que se logra es la no aplicación del impuesto (en principio de manera temporal), pese a que media un hecho imponible. Mediante la inafectación, en cambio,

1. Según lo dispuesto por el Decreto Legislativo 882 las Instituciones Educativas Particulares (tales como centros y programas educativos, cualquier que sea su nivel o modalidad, institutos y escuelas superiores, universidades y escuelas de posgrado), pueden organizarse jurídicamente bajo cualquiera de las formas previstas en el derecho común y en el régimen societario (como por ejemplo las Sociedades Anónimas), incluyendo las de asociación civil, fundación, cooperativa, empresa individual de responsabilidad limitada y empresa unipersonal. 
lo que se hace es apartar del hecho generador el tributo la actividad realizada por el contribuyente o incluso al contribuyente mismo por razones de su propia naturaleza. No existe, por consiguiente, el hecho imponible.

Este criterio ha sido recogido por el Tribunal Fiscal, el cual en la Resolución No. 559-4-97 se pronuncia respecto a la diferencia de los referidos términos:

\section{"(...) que la "inafectación" se refiere a una situación que no sido comprendida dentro del campo de aplicación del tributo, es decir, que está fuera porque no corresponde a la des- cripción legal hipotética y abstracta del hecho concreto (hipótesis de incidencia), en tanto que el término "exoneración" se refiere a que, no obstante que la hipótesis de incidencia prevista legalmente se verifica en la realidad, es decir, se produce el hecho imponible, éste por efectos de una norma legal no da lugar al nacimiento de la obligación tributaria, por razones de carácter objetivo o subjetivo (...)".}

Bajo el régimen de la Constitución de 1979 las universidades gozaban de una EXONERACIÓN que alcanzaba a TODO TRIBUTO. Estando ellas vigente se dictó la Ley Universitaria que contenía una exoneración, mientras que la actual Constitución prevé una INAFECTACIÓN y únicamente de IMPUESTOS.

A propósito de ello debemos recordar que el término tributo ${ }^{2}$ es mucho más amplio, en la medida que abarca tanto a los impuesto, como las tasas y contribuciones, encontrándose dentro de esta última clasificación, entre otras los arbitrios, derecho y licencias.

De este modo, resulta indispensable determinar si el régimen tributario previo, que reconocía la exoneración de todo tipo de tributo, pue- de considerarse valido y vigente a la luz de la Constitución de 1993, norma que en principio amplió los beneficios al establecer la inafectación, pero a su vez restringió este beneficio solo a los impuestos, excluyendo en consecuencia las contribuciones y tasas.

En ese sentido, nos debemos preguntar si el artículo 87 de la Ley 23733 - Ley Universitaria es compatible con la Constitución de 1993 y, por lo tanto, aplicable.

Dicha pregunta ha sido respondida por el Tribunal Constitucional que en los procesos iniciados por la Universidad Nacional de la Amazonía Peruana (Expediente No. 064032006-PA/TC) y la Universidad Nacional Federico Villareal señalo que:

"(...) la evaluación de compatibilidad o disconformidad del artículo 87 de la Ley 23733 frente al régimen tributario de las universidades dispuesto en la constitución de 1993 deberá tomar en cuenta los criterios de temporalidad y jerarquía.

La aplicación del criterio de temporalidad (lex posterior derogat legi anteriori) se encuentra reconocido en el artículo 103 de la Constitución Política y su aplicación trae como consecuencia el cese de la vigencia o derogación de la norma más antigua por la norma nueva. Como es evidente, el efecto derogatorio que despliega la implantación de un nuevo texto constitucional sólo alcanza a aquellas normas cuyo contenido sea contrario a lo que la Constitución dispone. Tal derogación es automática y se produce ex constitutione, sin necesidad de la declaración alguna por parte del legislador o de algún tribunal.

En el presente caso, se advierte que la Constitución de 1993 regula de distinta

2. La norma II del Título Preliminar del Código Tributario señala que el término genérico tributo comprende: (a) el Impuesto, que es el tributo cuyo cumplimiento no origina una contraprestación directa a favor del contribuyente por parte del Estado; (b) la Contribución, que es el tributo cuya obligación tiene como hecho generador beneficios derivados de la realización de obras públicas o de actividades estatales; y, (c) la Tasa, que es el tributo cuya obligación tiene como hecho generador la prestación efectiva por el Estado de un servicio público individualizado en el contribuyente. 
forma la materia que la Ley Universitaria (exoneraciones a las universidades con respecto a los tributos internos), por lo cual se debe concluir que la Ley No. 23733 ha sido derogada de manera tácita por la Constitución de 1993.

El criterio de jerarquía (lex superior derogat legi inferiori) se encuentra reconocido en el artículo 51 de la Constitución Política, el mismo que dispone que la Constitución prevalece sobre toda norma de rango legal; la ley, sobre las normas de inferior jerarquía, y así sucesivamente. Este artículo afirma los principios de supremacía constitucional que supone una normatividad supra - la Constitución - encargada de consignar la regulación normativa básica de cual emana la validez de todo el ordenamiento legal de la sociedad política. En ese entendido, se debe señalar que la Constitución es una norma jerárquicamente superior a la Ley No. 23733 por cuanto la validez de ésta depende de aquélla.

La validez, por tanto, en materia de justicia constitucional se encuentra relacionada con el principio de jerarquía normativa, conforme al cual la norma inferior (la Ley No. 23733) será válida sólo en la medida que sea compatible con la norma superior (la Constitución). De acuerdo a ello, el hecho que el artículo 87 de la Ley No. 23733 sea materialmente incompatible con la Constitución de 1993 traería como consecuencia la invalidez de aquellas, lo que a diferencia de la simple derogación supone que la misma no podrá seguir surtiendo ningún tipo de efectos con respecto a la recurrente".

De lo expuesto por el Tribunal Constitucional, podemos concluir claramente que el artículo 87 de la Ley 23733 - Ley Universitaria no es aplicable por ser incompatible con la Constitución de 1993, al pretender abarcar, en mayores supuestos, los beneficios tributarios establecidos en la Constitución.
En tal sentido, el régimen tributario vigente para las universidades es el regulado por el artículo 19 de la constitución de 1993, el cual establece que dichas instituciones se encuentran INAFECTAS al pago de IMPUESTOS.

\section{RÉGIMEN TRIBUTARIO VIGENTE DE LAS UNIVERSIDADES}

Tal como lo hemos señalado en los párrafos precedentes, actualmente la norma que regula el régimen tributario de las universidades es el artículo 19 de la Constitución de 1993, la cual establece que:

"Las universidades, institutos superiores y demás centros educativos constituidos conforme a la legislación en materia gozan de inafectación de todo impuesto directo o indirecto que afecte los bienes, actividades y servicios propios de su finalidad educativa y cultural. En materia de aranceles de importación, puede establecerse un régimen especial de afectación para determinados bienes.

Las donaciones y becas con fines educativos gozarán de exoneración y beneficios tributarios en la forma y dentro de los límites que fije la ley.

La ley establece que los mecanismos de fiscalización a que se sujetan las mencionadas instituciones, así como los requisitos y condiciones que deben cumplir los centros culturales que por excepción puedan gozar de los mismos beneficios.

Para las instituciones educativas privadas que generen ingresos que por ley sean calificados como utilidad, puede establecerse la aplicación del Impuesto a la Renta".

De la norma expuesta, se desprende que la Constitución limita la potestad tributaria del Estado a través de la inafectación al pago de impuestos a las universidades, institutos superiores y demás centros educativos. ${ }^{3}$

3. Tal criterio ha sido recogido por el Tribunal Constitucional en las Sentencias No. 1271-2006-AA/TC y No. 34442004-AA. 
Dicha inafectación se encuentra condicionada a los siguientes requisitos: (a) que las universidades, institutos superiores y demás centros educativos se encuentren constituidos conforme a la legislación de la materia; y, (b) que el impuesto, sea directo o indirecto, tenga efecto sobre los bienes, actividades y servicios propios de su finalidad educativa y cultural.

Sobre este particular, debemos señalar lo siguiente:

Tratándose del primer requisito, la legislación sobre la materia establece los elementos mínimos que deberán cumplir las universidades para ser creadas, como por ejemplo la acreditación de la necesidad para su creación, así como la disponibilidad del personal docente calificado y los recursos que aseguren la eficiencia de sus servicios. Asimismo las universidades deben ser mediante Ley.

Tratándose del segundo requisito, la constitución estableció los incentivos con el fin de promover la educación, razón por la cual la inafectación solo alcanza a los bienes, actividades y servicios propios de la finalidad educativa y cultura; es decir que solo se encontraran inafectos los ingresos que se destinen únicamente a la finalidad educativa y cultural. Creemos que dentro de este requisito también se encuentran comprendidos los supuestos en los que los bienes, actividades y servicios están vinculados al desarrollo de actividades distintas a las educativas y culturales, pero los fondos obtenidos por su realización si van a estar efectivamente destinados al desarrollo educativo y cultural.

Es por ello que se debe tener un especial cuidado al considerar un operación como no gravada, toda vez que existen operaciones que no gozaran de la inafectación toda vez que ellos no necesariamente se encuentran dentro de la finalidad educativa y cultural de la Universidad.

De otro lado, según lo dispuesto por la norma constitucional, los tributos que se consideran inafectos son los impuestos. Estos, según lo establecido por la Norma II del Código Tributario, son los tributos cuyo cumplimiento no origina una contraprestación directa a favor del contribuyente por parte del Estado.

Los impuestos se dividen en directo e indirectos. Los primeros son aquellos que tienen relación con la capacidad tributaria directamente ligada con un elemento subjetivo: las características del contribuyente y los ingresos que el mismo percibe. No se permite la traslación del impuesto. Por otro lado, los impuestos indirectos hacen posible la diferencia entre el sujeto que es obligado a pagar el tributo y el sujeto económico, quien fácticamente soporta la carga, mediante la traslación. tipos de impuestos, ${ }^{4}$ sea cual fuere su clasificación, se encuentran comprendidos en la inafectación establecida en la Constitución de 1993.

A continuación detallaremos brevemente el tratamiento de los principales impuestos regulados en el Perú a la luz de la inafectación contenida en el artículo 19 de la Constitución.

\section{Impuesto a la Renta}

Tal como se ha indicado, el primer párrafo del artículo 19 de la Constitución de 1993 establece que: "(...) las universidades, institutos superiores y demás centros educativos gozan de inafectación de todo impuesto directo o indirecto que afecte los bienes, actividades y servicios propios de su finalidad educativa y cultural". Asimismo, el cuarto párrafo de la mencionada norma señala que: "(...) para las instituciones educativas privadas ${ }^{5}$

4. El Decreto Legislativo 771 - Ley Marco del Sistema Tributario Nacional - regula la estructura del sistema tributario peruano, identificando, en concordancia con el Código Tributario, tres subconjuntos de tributos en función del destinatario de los montos recaudados. Así, en cuanto a impuestos, identifica el Impuesto a la Renta, el Impuesto General a las Ventas y el Impuesto Selectivo al Consumo. En materia de tributación identifica al Impuesto Predial, la Alcabala, el Impuesto Vehicular, Impuesto a los Espectáculos no Deportivos, Impuesto a la Promoción Municipal, entre otros.

5. Según el Decreto Supremo 047-97-EF se debe entender como institución educativa a las personas naturales, sucesiones indivisas, asociaciones de hecho de profesionales y similares y las organizaciones jurídicamente bajo 
que generan ingresos que por Ley sean calificados como utilidades, pueden establecerse la aplicación del Impuesto a la Renta (...)".

Ahora bien, según el artículo 12 del Decreto Legislativo 882 , se entenderá por utilidad a la diferencia que exista ente los ingresos totales obtenidas por las instituciones educativas y los gastos necesarios para producirlos y mantener su fuente, constituyendo la renta neta. Asimismo, señala que a fin de la determinación del impuesto a la Renta correspondiente se aplicaran las normas generales del referido impuesto.

De otro lado, el artículo 11 del Decreto Legislativo 882 , señala que las que las instituciones educativas particulares se regirán por las normas del régimen general del Impuesto a la Renta.

De las citadas normas podemos concluir que las instituciones educativas públicas no están sujetas al Impuesto a la Renta, mientras que las instituciones educativas particulares se rigen por lo dispuesto en la propia Ley del Impuesto a Renta y su Reglamento.

Para estos efectos, debemos señalar que el inciso i) del artículo 28 de la Ley del Impuesto a la Renta, establece que son rentas de tercera categoría las obtenidas por las instituciones educativas particulares. Asimismo, el inciso b) del artículo 19 de la citada Ley indica que se encuentran exoneradas del Impuesto a la Renta hasta el 31 de diciembre de 2011, las rentas obtenidas por las asociaciones sin fines de lucro cuyo instrumento de constitución comprenda exclusivamente fines educativos, entre otros, siempre que destinen sus rentas a fines específicos en el país; no las distribuyan, directa o indirectamente, entre los asociados y que en sus estatutos esté previsto que su patrimonio se destinará, en caso de disolución a cualquiera de los fines contemplados en el inciso b) del citado artículo.
De lo expuesto podemos concluir que los ingresos obtenidos por instituciones educativas privadas se encuentran gravados con el Impuesto a la Renta, salvo que estas instituciones se hayan constituido como asociaciones sin fines de lucro, en cuyo caso se encuentran exoneradas del Impuesto a la Rentas hasta el 31 de diciembre de 2011.

Finalmente, debemos señalar que mediante el artículo 13 del Decreto Legislativo se estableció un beneficio tributario, por el cual las instituciones educativas particulares, que reviertan total o parcialmente la utilidad generada en sí mismas o en otras instituciones educativas particulares, constituidas en el país, tendrán derecho a un crédito tributario por reinversión equivalente al 30\% del monto reinvertido. Dicha norma empezó a regir a partir del 01 de enero de 1997.

Ahora bien, somos de la opinión que dicho beneficio se encontró vigente hasta el 31 de diciembre de 1999.

En efecto, dicho beneficio fue aprobado sin señalar un plazo de vigencia, y por lo tanto en dicho caso aplicaba la norma VII del Título Preliminar del Código Tributario (vigente en el momento de aprobación del Decreto Legislativo 882 pero actualmente derogada), la cual establecía que "toda exoneración o beneficio tributario concedido sin señalar plazo se entenderá otorgado por tres años (...) no hay prórroga tácita (...)".

En el presente caso, al no haberse determinado un plazo de vigencia del beneficio tributario, y de acuerdo a lo establecido en la norma VII, se encontró vigente hasta el 31 de diciembre de 1999.

En tal sentido, la Ley 29766 (norma que precisó que lo beneficios tributarios señalados en el Decreto Legislativo 882, dentro de los cuales se encuentra el crédito por reinversión, caducaron

cualquiera de las formas previstas en el derecho común y en el régimen societario que, con o sin ánimo de lucro, se dedican con carácter exclusivo a la prestación de servicios educativos, en cualquiera de los niveles y modalidades previstos por la Ley. 
a la entrada en vigencia del Decreto Legislativo 1087, es decir hasta el 29 de junio de 2008), en nuestra opinión no es aplicable toda vez que a través de esta supuesta norma de precisión se está intentando ampliar un beneficio hasta el año 2008, a pesar que el mismo ya venció el 31 de diciembre de 1999.

\section{Impuesto General a las Ventas}

La Ley del Impuesto General a las Ventas e Impuesto Selectivo al Consumo señala en su artículo 2 que no están gravadas con el Impuesto General a las Ventas "Ias transferencias o importación de bienes y la prestación de servicios que efectúen las instituciones educativas públicas o particulares exclusivamente para sus fines propios ${ }^{6 \prime}$. Asimismo, la mencionada norma señala que mediante Decreto Supremo se aprobará la relación de bienes y servicios inafectos al pago del Impuesto General a la Ventas

La última relación de bienes y servicios inafectos al pago del Impuesto General a las Ventas fue aprobada mediante el Decreto Supremo 046-97$\mathrm{EF}$, la cual incluye los siguientes bienes y servicios:

Los servicios educativos vinculados a la preparación inicial, primaria, secundaria, superior, especial, ocupacional, entre otros. Estos servicios incluyen los derechos de inscripción, matrículas, exámenes, pensiones, asociaciones de padres de familia, seguro médico educativo y cualquier otro concepto cobrado por el servicio educativo.

La expedición de constancias, certificados, diplomas y similares.
Las actividades de bibliotecas, hemerotecas, archivos, museos, cursos, seminarios, exposiciones, conferencias y otras actividades educativas complementarias al servicio de enseñanza ${ }^{7}$.

Los servicios de alojamiento y alimentación a estudiantes así como el transporte exclusivo para estudiantes, prestados por la misma institución educativa.

- La venta de libros, folletos, revistas, publicaciones y cualquier información que apoye el proceso educativo, presentado en medios impresos, magnéticos o digitales, para uso exclusivo de alumnos y docente regulares de la Institución.

- La transferencia de bienes usados del activo fijo de propiedad de las instituciones educativas.

Los servicios educativos prestados entre instituciones educativas.

Como se aprecia de las citadas normas, la Ley del Impuesto General a las Ventas recoge lo señalado por el artículo 19 de la Constitución y establece que se encuentran inafectos del Impuesto General a las Ventas las operaciones que las entidades educativas públicas o particulares realicen exclusivamente para sus fines propios.

Lo que si hace la Ley del Impuesto General a las Ventas, es limitar (o en todo caso definir) la inafectación a ciertas operaciones que esta ley considera como exclusiva para la realización de los fines propios de estas instituciones.

6. Según lo dispuesto por la disposición Transitoria Única, se consideran fines propios de las instituciones educativas particulares o públicas: (a) la formación educativa en materia de humanidades, la ciencia, la técnica, las artes, la educación física y el deporte; (b) la difusión cultural; (c) la creación intelectual y artística; y, (d) la investigación científica y tecnológica.

7. De conformidad con lo dispuesto por el artículo 1 del Decreto Supremo 081-2003-EF las actividades educativas prestadas por las instituciones educativas particulares o públicas mediante cursos, seminarios y similares comprenden aquellas actividades educativas prestadas a estudiantes regulares o no, que puedan conducir o no a una certificación; siempre que estén comprendidas dentro de los alcances de las normas que regulan las actividades de las instituciones educativas y cuente con la autorización respectiva, por la autoridad correspondiente. 


\section{Impuesto Predial}

Las universidades y centros educativos, debidamente reconocidos, se encuentran inafectos al pago del impuesto a los predios respecto de los inmuebles de su propiedad, siempre y cuando estos inmuebles se encuentren destinados a sus finalidades educativas y culturales.

Así como reconoce el Tribunal Fiscal en la Resolución No. 5645-4-2002 que señala que:

"(...) la universidad recurrente se encuentra inafecta al Impuesto Predial, en tanto se trata del predio destinado al campus universitario; es decir, dedicado a sus fines, siendo ello de aplicación tanto a universidades públicas como privadas".

De otro lado, en caso de los predios de las universidades que produzcan renta (mediante alquileres o cesiones a título oneroso, entre otros), dichas instituciones deberán pagar el Impuesto Predial correspondiente. Así lo reconoce el Tribunal Fiscal en la Resolución No. 1792-4-2003, en la cual se señala que:

"(...) se establece que las Universidades se encuentran inafectas del Impuesto Predial, siempre que sus predios no produzcan renta, lo que se cumple en el caso de autos por cuanto no están alquilados ni cedidos a título oneroso a un tercero, y en tanto dichos predios están empleados para los fines propios de la actividad educativas inherente de la Universidad (...)".

\section{Alcabala}

La Ley de Tributación Municipal en concordancia con lo dispuesto por la constitución ha establecido que se encuentran inafectas al pago del Alcabala, la adquisición de propiedad inmobiliaria que efectúen las universidades.

\section{Arbitrios}

Tal como lo hemos señalado la Norma II del Título Preliminar del Código Tributario señala que existen tres clases de tributos: (i) impuestos; (ii) contribuciones; $y$, (iii) tasas. De acuerdo a tal norma, los impuestos constituyen tributos cuyo cumplimiento no origina una contraprestación directa a favor del contribuyente por parte del Estado. En cambio, las tasas son tributos cuya obligación tiene como hecho generador la prestación efectiva por el Estado de un servicio público individualizado en el contribuyente.

Ahora bien, la citada norma califica a los arbitrios como una subespecie de las tasas, definiéndolas como aquellas que se pagan por la prestación o mantenimiento de un servicio público. La misma calificación adopta el artículo 69 del Texto Único Ordenado de la Ley de Tributación Municipal (Aprobado mediante el Decreto Supremo 156-2004-EF), el cual dispone que: las tasas por servicios públicos o arbitrios, se calcularan dentro del último trimestre de cada ejercicio fiscal anterior al de su aplicación, en función del costo efecto del servicios a prestar.

De acuerdo a ello, los arbitrios pertenecen a una especie tributaria distinta de los impuestos, por lo que no se encuentran incluidos dentro del supuesto de inafectación que prevé el artículo 19 de la Constitución Política a favor de las universidades; siendo así, este tributo resulta exigible a dichas entidades educativas.

Dicho criterio ha sido recogido por el Tribunal Fiscal en la Resolución No. 6528-2-2005 que señala que:

“(...) durante la vigencia de la Constitución Política de 1979 se estableció que las universidades, entre otras entidades, se encontraban exoneradas de todo tributo $y$, en consecuencia de los arbitrios, disposición que al ser constitucional primaba sobre otra norma de menor jerarquía. Por ello, las municipalidades no podían gravar a dichas entidades en virtud de la norma constitucional, lo que era a su vez recogido por la Ley General de Educación y por la Ley Universitaria.

A partir de la entrada en vigencia de la actual Constitución Política, en virtud de su potestad tributaria, pueden gravar con arbitrios municipales, toda vez que el texto constitucional 
únicamente exonera a dichas entidades de impuestos, no así de contribuciones y tasas (...)".

\section{CONCLUSIONES}

1. En virtud del artículo 19 del Constitución las universidades se encuentran inafectas de todo impuesto siempre que se encuentren constituidos conforme a la legislación de la materia y que el impuesto tenga efecto sobre los bienes, actividades y servicios propios de su finalidad educativa y cultural.

2. Respecto al Impuesto a la Renta, el artículo 19 de la Constitución establece un trata- miento distinto para las universidades particulares o privadas, señalando que dichas instituciones no se encuentran inafectas del dicho impuesto.

3. La Ley del Impuesto a la Renta exonera de dicho impuesto a la universidades particulares o privadas que hayan sido constituidas bajo la forma de una asociación sin fines de lucro hasta el 31 de diciembre de 2011.

4. El beneficio de reinversión otorgado a las entidades educativas particulares se encontró vigente hasta el 31 de diciembre de 1999. 